\title{
Associations of Diabetes and Obesity with Risk of Abdominal Aortic Aneurysm in Men
}

\author{
Lu Wang, ${ }^{1}$ Luc Djousse, ${ }^{2,3}$ Yiqing Song, ${ }^{4}$ Akintunde O. Akinkuolie, ${ }^{1}$ Chisa Matsumoto, ${ }^{5}$ \\ JoAnn E. Manson, ${ }^{1,6}$ J. Michael Gaziano, ${ }^{1,2,3}$ and Howard D. Sesso ${ }^{1,2,6}$ \\ ${ }^{1}$ Division of Preventive Medicine, Department of Medicine, Brigham and Women's Hospital, Boston, MA, USA \\ ${ }^{2}$ Division of Aging, Department of Medicine, Brigham and Women's Hospital, Boston, MA, USA \\ ${ }^{3}$ Massachusetts Veterans Epidemiology Research and Information Center and Geriatric Research, Education, and Clinical Center, \\ VA Boston Healthcare System, Boston, MA, USA \\ ${ }^{4}$ Department of Epidemiology, Indiana University Richard M. Fairbanks School of Public Health, Indianapolis, IN, USA \\ ${ }^{5}$ Department of Clinical Epidemiology, Division of Cardiology, Tokyo Medical University Hospital, Tokyo, Japan \\ ${ }^{6}$ Department of Epidemiology, Harvard T.H. Chan School of Public Health, Boston, MA, USA \\ Correspondence should be addressed to Lu Wang; luwang@rics.bwh.harvard.edu
}

Received 1 November 2016; Accepted 29 January 2017; Published 23 February 2017

Academic Editor: Chris I. Ardern

Copyright (C) $2017 \mathrm{Lu}$ Wang et al. This is an open access article distributed under the Creative Commons Attribution License, which permits unrestricted use, distribution, and reproduction in any medium, provided the original work is properly cited.

\begin{abstract}
Background. The associations of diabetes and obesity with the risk of abdominal aortic aneurysm (AAA) are inconclusive in previous studies. Subjects/Methods. We conducted prospective analysis in the Physicians' Health Study. Among 25,554 male physicians aged $\geq 50$ years who reported no AAA at baseline, 471 reported a newly diagnosed AAA during a mean of 10.4 years' follow-up. Results. Compared with men who had baseline body mass index (BMI) $<25 \mathrm{~kg} / \mathrm{m}^{2}$, the multivariable hazard ratio (HR [95\% CI]) of newly diagnosed AAA was 1.30 [1.06-1.59] for BMI $25-<30 \mathrm{~kg} / \mathrm{m}^{2}$ and $1.69[1.24-2.30]$ for BMI $\geq 30 \mathrm{~kg} / \mathrm{m}^{2}$. The risk of diagnosed AAA was significantly higher by $6 \%$ with each unit increase in baseline BMI. This association was consistent regardless of the other known AAA risk factors and preexisting vascular diseases. Overall, baseline history of diabetes tended to be associated with a lower risk of diagnosed AAA ( $\mathrm{HR}=0.79$ [0.57-1.11]); this association appeared to vary by follow-up time $(\mathrm{HR}=1.56$ and 0.63 during $\leq$ and $>2$ years' follow-up, resp.). Conclusion. In a large cohort of middle-aged and older men, obesity was associated with a higher risk, while history of diabetes tended to associate with a lower risk of diagnosed AAA, particularly over longer follow-up.
\end{abstract}

\section{Introduction}

Abdominal aortic aneurysm (AAA), defined as a localized dilatation of the abdominal aorta, is a significant cause of morbidity [1-3] and mortality [4-6] in aging populations. Multiple risk factors for atherosclerosis, including advanced age, male sex, smoking, hyperlipidemia, and hypertension, are associated with an increased risk of AAA [7]. However, laboratory and epidemiologic studies have suggested that the etiology of AAA may be different from the occlusive atherosclerotic disease [8].

Although individuals with diabetes have a higher risk of occlusive atherosclerotic disease, data from large-scale screening [9-13] and disease registry [14] have shown a paradoxically lower prevalence of AAA in diabetic patients. One possible explanation is that AAA may be particularly lethal in diabetic patients, and thus fewer people have both conditions at the same time. Nevertheless, other findings do not support this hypothesis. AAA progresses more slowly in diabetics [15-18] and diabetic patients are less likely to have a ruptured AAA at the time of repair [19], suggesting that diabetes or its medications may protect against the development and improve the prognosis of AAA. Meanwhile, obesity has been implicated in the pathogenesis of both diabetes and atherosclerosis, for which the key mechanisms include insulin resistance and release of adipokines. Data on 


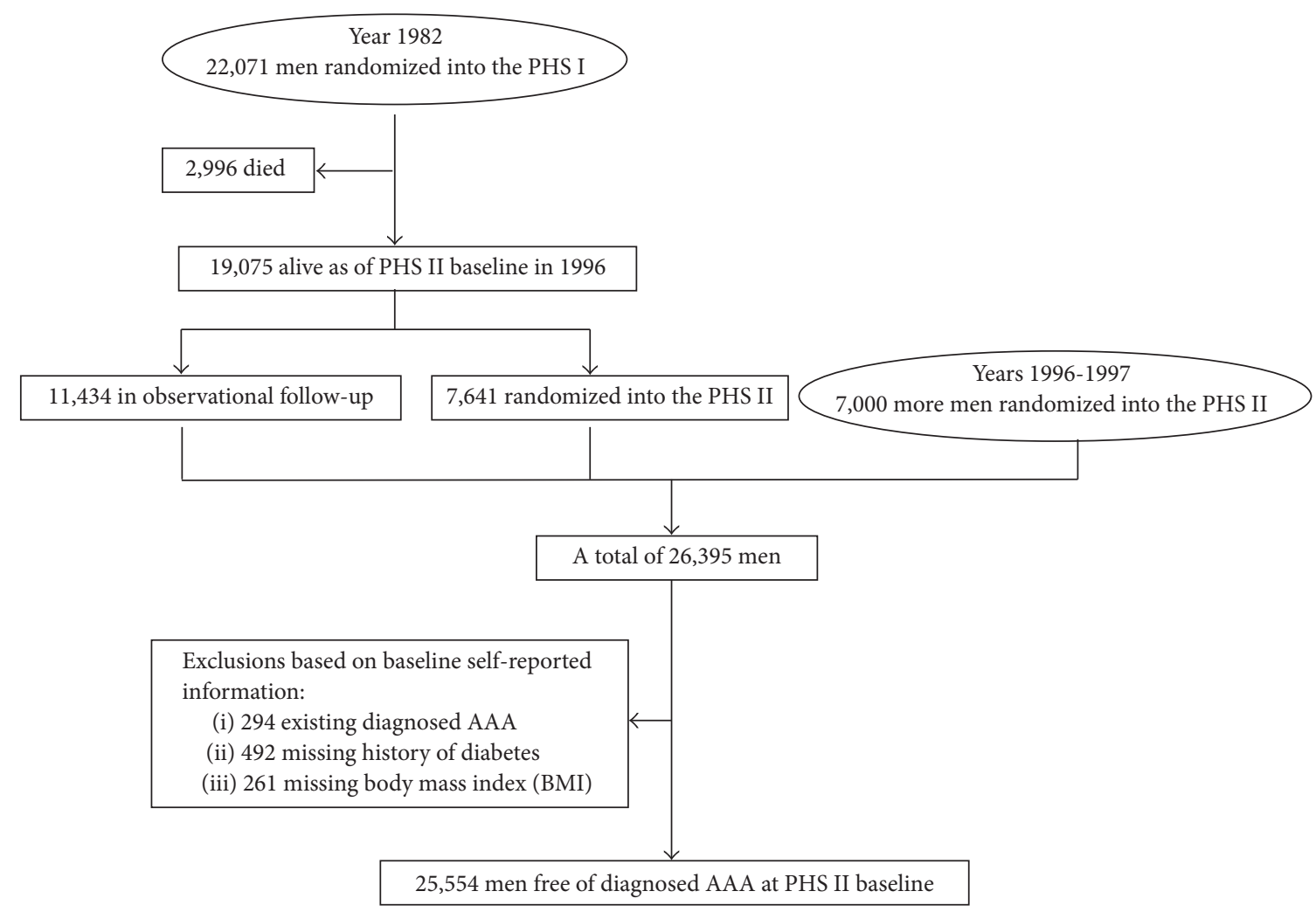

FIGURE 1: Flow diagram of participants in the Physicians' Health Study (PHS) I and II that are included in the current analysis.

the associations between measures of obesity and AAA are inconsistent; direct [20], inverse [21], and null [22] associations have all been reported. Understanding the complex associations of diabetes and obesity with AAA could provide important insight into the unique etiology of AAA and guide more effective prevention and treatment strategies.

To further elucidate the association between diabetes and obesity with the risk of AAA, we conducted a prospective analysis in a large cohort of US male physicians who reported clinical diagnosis of AAA over a mean of 10.4 years' followup.

\section{Materials and Methods}

2.1. Study Population. The Physicians' Health Study (PHS) consists of two completed randomized clinical trials. The PHS I was a randomized, double-blind, placebo-controlled $2 \times 2$ factorial trial testing aspirin and $\beta$-carotene in the primary prevention of cardiovascular disease (CVD) and cancer among 22,071 US male physicians aged 40-84 years in 1982 [23]. The PHS II was a $2 \times 2 \times 2 \times 2$ factorial trial testing $\beta$-carotene, vitamin $\mathrm{E}$, vitamin $\mathrm{C}$, and a multivitamin in the prevention of CVD, cancer, eye disease, and cognitive function among 14,641 US male physicians aged $\geq 50$ years in 1996-1997, including 7,641 PHS I participants and 7,000 newly recruited physicians [24]. All interventions in PHS have ended and follow-up continues as an ongoing observational study. Both trials and posttrial observational follow-up were approved by the Brigham and Women's Hospital institutional review board. All participants provided written informed consent.

For the current study, we included 19,075 PHS I participants who were alive at PHS II baseline starting in 1996, plus 7,000 newly recruited PHS II participants for analysis (Figure 1). We excluded those with missing information on baseline body mass index (BMI) $(n=261)$ or history of diabetes $(n=492)$. We also excluded 294 participants who reported a history of AAA at PHS II baseline. As a result, 25,554 men initially free of clinically diagnosed AAA were included for analyses.

2.2. Identification of Diagnosed Abdominal Aortic Aneurysm. PHS II participants were asked to report a clinical diagnosis (including month and year of diagnosis) of AAA on enrollment and each annual follow-up questionnaire. We used ICD-9 codes of 441.3 (ruptured AAA) and 441.4 (AAA without mention of rupture) to identify AAA. Incident cases were defined as men who were free of diagnosed AAA at baseline and reported a newly diagnosed AAA during followup. Through March 2012, a total of 471 newly diagnosed AAAs were reported, with 427 cases also reporting the date of diagnosis. For the 44 cases that did not report the diagnosis date, the date of event was assigned to when the annual questionnaire with reported AAA was received. Only three of these 44 cases had missed an adjacent annual follow-up before the self-report of AAA, for whom the interval between the actual and the assigned diagnosis date may be longer. 
A previous study has validated self-reported AAA repair and rupture by extensive medical record review and demonstrated sensitivity and specificity of $90 \%$ and $100 \%$, respectively [25]. In a validation study in PHS, we reviewed medical records for a subset of 77 participants who reported AAA and subsequently developed major CVD events including myocardial infarction and stroke. Clinically diagnosed AAAs were confirmed in 47 (61\%) of the 77 self-reported cases, with documented imaging examinations $(n=15)$, repair procedures $(n=33)$, or rupture events $(n=2)$. Of the remaining self-reported cases, we could not confirm nor disconfirm AAA based on available records. Since this validation study used medical records that were retrieved primarily for adjudication of myocardial infarction and/or stroke, it is possible that the diagnosis of less severe CVD conditions such as untreated and unruptured small AAA may not be recorded. We anticipate a higher confirmation rate if medical records were more extensively searched for AAA diagnoses.

2.3. Baseline Covariates. On the PHS II baseline questionnaires, men provided self-reports of age (in years), height and weight (used to calculate BMI in $\mathrm{kg} / \mathrm{m}^{2}$ ), cigarette smoking (never, past, and current), alcohol use (none, monthly, weekly, and daily), and vigorous exercise (none, 1-3 times/month, 1-2 times/week, 3-4 times/week, and 5-7 times/week). Diabetes (yes, no) was defined by the history of a physician diagnosis. In a previous validation study conducted in a subsample of PHS participants, diabetes was confirmed in 59 (98.3\%) of 60 self-reported cases via medical record view by two independent physicians [26]. Hypertension was defined by any history of antihypertensive treatment, self-reported systolic blood pressure $\geq 140 \mathrm{mmHg}$, or diastolic blood pressure $\geq$ $90 \mathrm{mmHg}$. Hyperlipidemia was defined by the history of a physician diagnosis, cholesterol-lowering treatment, or selfreported total cholesterol $\geq 240 \mathrm{mg} / \mathrm{dL}$.

2.4. Data Analyses. All statistical analyses were conducted using SAS (SAS Institute, Cary, NC, USA) version 9.3, with a two-sided significance level at 0.05 . We first compared the baseline characteristics of men who reported newly diagnosed AAA with those who did not. The association of diagnosed AAA with known risk factors was assessed using generalized linear models for continuous variables or chi-square tests for categorical variables. Cox proportional hazards regression models estimated the hazard ratios (HRs) and 95\% CIs of diagnosed AAA in association with baseline BMI and history of diabetes. Person-years of follow-up were calculated for each participant from PHS II baseline to the date of AAA diagnosis, the date of last known information, or March 2012, whichever came first. BMI was modeled first as categorical variable (normal-weight: $<25 \mathrm{~kg} / \mathrm{m}^{2}$, overweight: $25-<30 \mathrm{~kg} / \mathrm{m}^{2}$, and obese: $\geq 30 \mathrm{~kg} / \mathrm{m}^{2}$ ) and then as continuous variable with a quadratic term included to assess possible curvilinearity. History of diabetes was modeled as a binary variable. The assumption of proportional hazard was violated in the model for history of diabetes ( $P$ for the interaction term of diabetes with logarithm of follow-up time $<0.05)$. We therefore estimated the HRs for diabetic versus nondiabetic men within and beyond the first 2 years of follow-up, after which the interaction term with logarithm of follow-up time was no longer significant. We considered known risk factors for AAA including age, race, smoking status, alcohol use, vigorous exercise, history of hypertension, hypercholesterolemia, and CVD as potential confounders and also possible effect modifiers. Interactions were tested by including product-terms. We also examined the cumulative incidence curve for diagnosed AAA according to baseline BMI and history of diabetes across entire follow-up time.

\section{Results}

Among 25,554 men who reported no AAA at PHS II baseline, 471 reported a new diagnosis of AAA during a mean of 10.4 (maximum: 14.5) years' follow-up. Compared with men who remained free of diagnosed AAA, those who had newly diagnosed AAA were older, had higher BMI and greater alcohol consumption, engaged in lower levels of vigorous exercise, were more likely to be current smokers, and have a history of hypertension, hypercholesterolemia, and CVD at baseline (Table 1). The proportion of men with history of diabetes at baseline was similar in those who did and did not have new diagnosis of AAA $(P>0.05)$.

After adjusting for age, race, and randomized treatment (aspirin, $\beta$-carotene, vitamin $\mathrm{E}$, vitamin $\mathrm{C}$, and multivitamin), the risk of diagnosed AAA was higher with increasing BMI at baseline (Table 2). Compared with men who had normal baseline BMI, the HR of diagnosed AAA was $1.44(95 \%$ CI: 1.18-1.75) for overweight men and 2.11 (95\% CI: 1.56-2.85) for obese men. After additional adjustment for lifestyle factors (smoking, alcohol use, and vigorous exercise) and clinical factors (history of hypertension, hypercholesterolemia, CVD, and diabetes), the associations were attenuated but remained statistically significant, with corresponding HRs of 1.30 (95\% CI: 1.06-1.59) and 1.69 (95\% CI: 1.24-2.30), respectively. These associations were consistent across categories of known AAA risk factors (all $P$ for interaction $>0.05$ ). The multivariable HRs of AAA for obese versus normal-weight men ranged from 1.38 to 1.87 in subgroups of age, smoking status, alcohol use, and vigorous exercise. Higher BMI was also associated with increased risk of clinically diagnosed AAA regardless of the presence or absence of CVD, hypertension, and hypercholesterolemia. In stratified analysis by history of diabetes, a positive association between BMI and risk of AAA was found only in men without, but not in those with, history of diabetes, but the interaction was not statistically significant $(P=0.30)$. Figure $2(a)$ showed that the cumulative incidence of AAA was higher among overweight and obese men than normal-weight men across the entire follow-up time. When BMI was modeled as a continuous variable, the risk of diagnosed AAA was $6 \%$ higher (multivariable HR: 1.06, 95\% CI: 1.03-1.08) for each unit increase in baseline BMI (data not shown).

Comparing diabetic versus nondiabetic men, the overall HR of clinically diagnosed AAA was 1.08 (95\% CI: $0.78-$ 1.50 ) in the basic model and 0.79 (95\% CI: $0.57-1.11$ ) in the multivariable model (Table 3 ). The lack of an association was consistent among men stratified by baseline age, smoking 


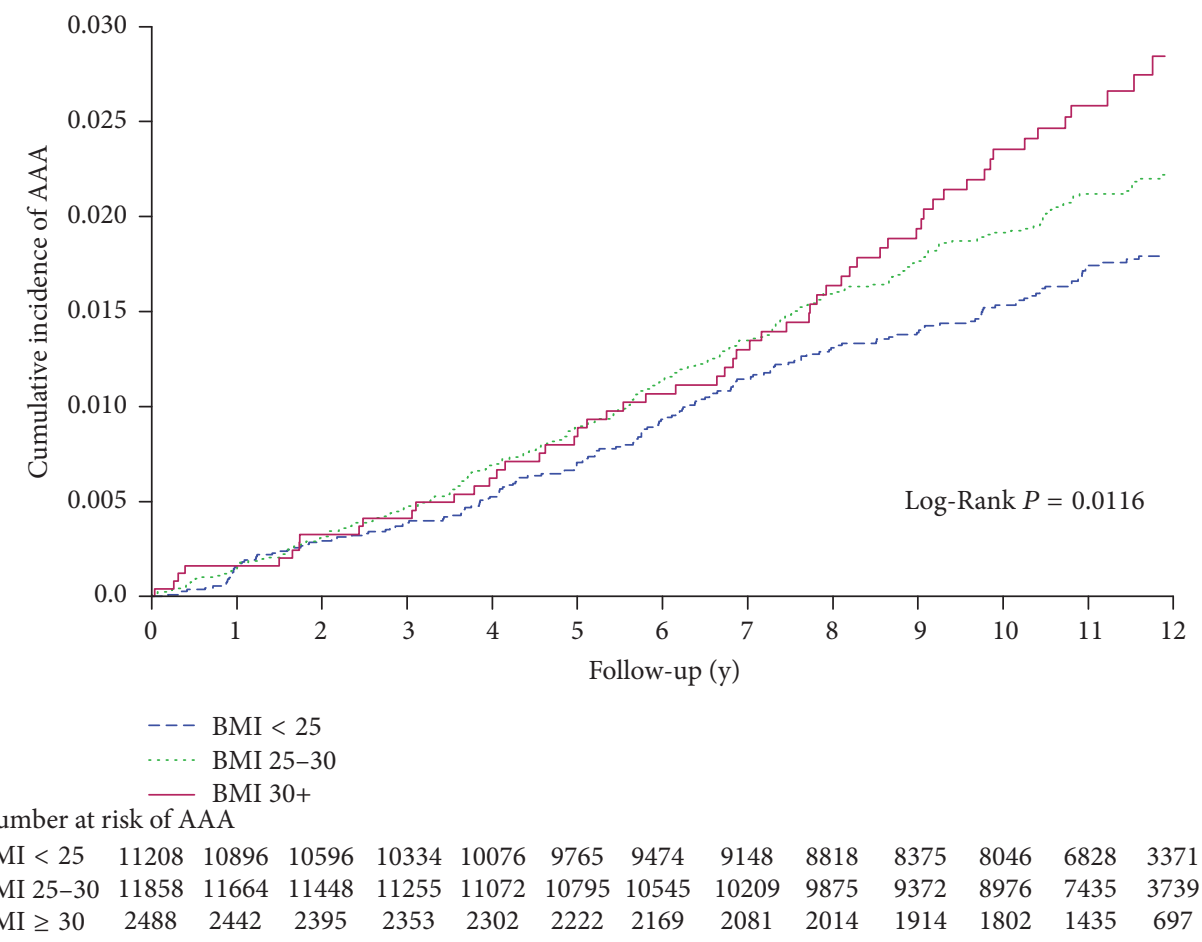

(a)

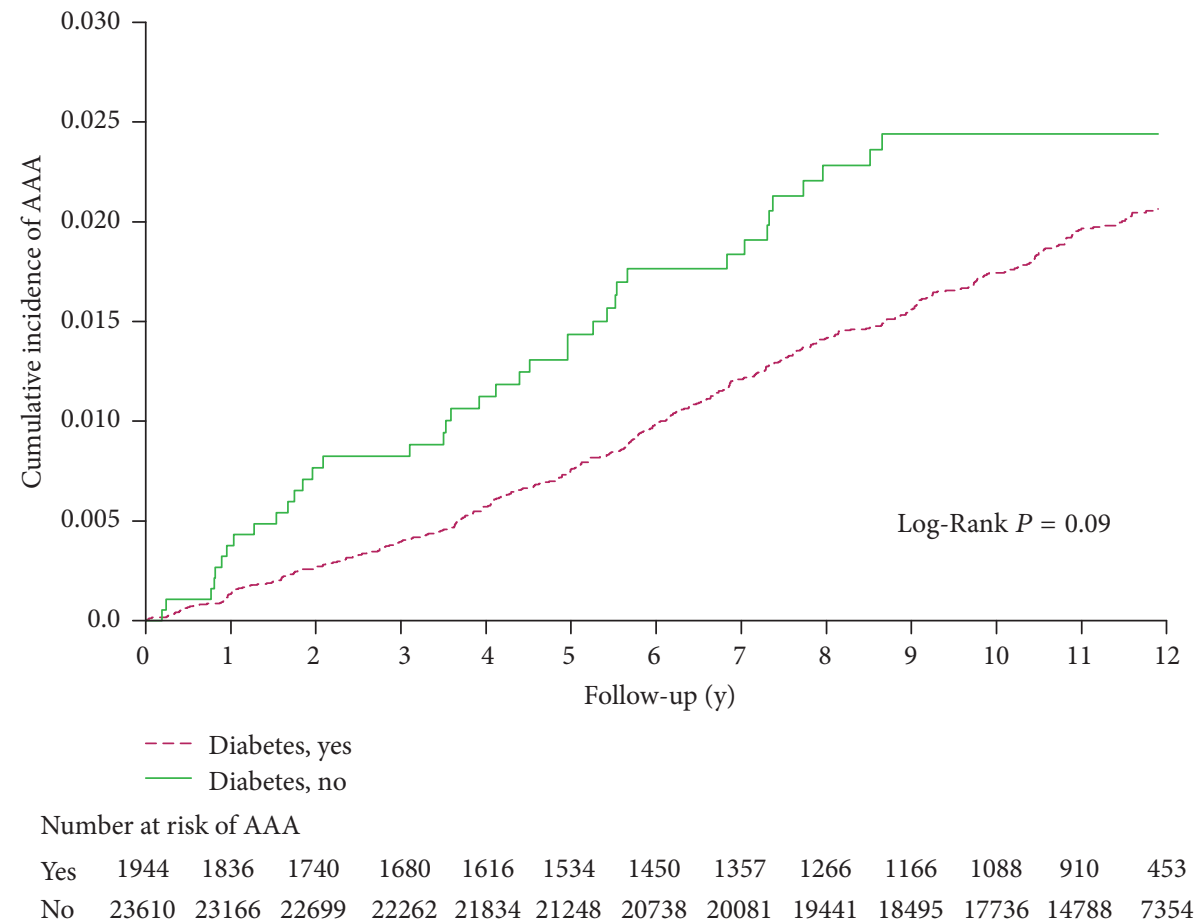

(b)

FIgURE 2: Cumulative incidence of clinically diagnosed AAA according to baseline BMI (a) and history of diabetes (b). Multivariable model adjusted for age, race, randomized treatment assignment, smoking status, alcohol use, vigorous exercise, history of cardiovascular disease, hypertension, and hypercholesterolemia. Model for BMI also adjusted for history of diabetes, and vice versa. 
TABLE 1: Baseline characteristics of men who had versus who did not have newly diagnosed abdominal aortic aneurysm (AAA) during a mean of 10.4 years' follow-up.

\begin{tabular}{|c|c|c|c|}
\hline Baseline characteristics & Newly diagnosed AAA & No AAA & $P^{*}$ \\
\hline$N$ & 471 & 25083 & \\
\hline Age, years & $70.8 \pm 7.4$ & $65.4 \pm 9.0^{\dagger}$ & $<0.0001$ \\
\hline White, $\%$ & 93.2 & $90.5^{\ddagger}$ & 0.11 \\
\hline Body mass index, $\mathrm{kg} / \mathrm{m}^{2}$ & $26.3 \pm 3.3$ & $25.8 \pm 3.4$ & 0.001 \\
\hline Smoking, \% & & & $<0.0001$ \\
\hline Never & 25.5 & 53.6 & \\
\hline Former & 62.4 & 42.8 & \\
\hline Current & 11.9 & 3.6 & \\
\hline Alcohol use, \% & & & 0.005 \\
\hline Never & 17.6 & 17.9 & \\
\hline Monthly & 7.6 & 7.1 & \\
\hline Weekly & 30.4 & 37.6 & \\
\hline Daily & 42.9 & 35.3 & \\
\hline Vigorous exercise, \% & & & 0.0004 \\
\hline Never & 44.4 & 35.4 & \\
\hline 1-3 times/month & 1.9 & 2.8 & \\
\hline 1-2 times/week & 11.9 & 15.9 & \\
\hline 3-4 times/week & 28.9 & 28.7 & \\
\hline$>5$ times/week & 12.3 & 15.4 & \\
\hline \multicolumn{4}{|l|}{ Disease history, \% } \\
\hline Cardiovascular disease & 23.1 & 11.2 & $<0.0001$ \\
\hline Diabetes & 8.5 & 7.6 & 0.46 \\
\hline Hypertension & 63.1 & 45.2 & $<0.0001$ \\
\hline Hypercholesterolemia & 51.4 & 41.0 & $<0.0001$ \\
\hline
\end{tabular}

${ }^{*} P$ for $t$-test for continuous variables and for chi-square test for categorical variables.

${ }^{\dagger}$ Mean $\pm \mathrm{SD}$ is shown for continuous variables.

${ }^{\ddagger}$ Percentages are shown for categorical variables.

status, alcohol use, vigorous exercise, history of hypertension, hypercholesterolemia, and CVD (all $P$ for interaction > 0.05). The association between history of diabetes and risk of diagnosed AAA appeared to vary by follow-up time; men with baseline diabetes had a slightly higher rate of diagnosed AAA during the first 2 years of follow-up (multivariable HR: 1.56, 95\% CI: 0.85-2.85), but significantly lower rate of AAA during prolonged follow-up beyond 2 years (HR: $0.63,95 \%$ CI: 0.42-0.94). Comparing the cumulative incidence curves of AAA for men with versus without baseline history of diabetes, the two curves diverged after the first 1-2 years of follow-up (Figure 2(b)).

\section{Discussion}

In this prospective cohort of US male physicians with a mean of 10.4 years' follow-up, we found that baseline obesity was associated with a higher risk of clinically diagnosed AAA. This association remained significant after adjusting for potential confounders and was consistent across categories of known AAA risk factors. In contrast, there is suggestive evidence that history of diabetes might be associated with a lower risk of diagnosed AAA that occurred after 2 years of follow-up. Our findings of the complex associations of diabetes and obesity with risk of AAA highlight a unique pathogenesis of AAA with important clinical and public health implications.

The majority of previous epidemiologic studies on diabetes and AAA have been cross-sectional studies [9-14] and noted an inverse correlation between presence of AAA and diabetes. Prospective studies remain only a few. In 161,808 postmenopausal women from Women's Health Initiative (WHI), baseline diabetes was inversely (odds ratio: 0.29, 95\% CI: 0.13-0.68) associated with AAA events that were symptomatic or required intervention and had been documented with a diagnostic or interventional procedure [27]. In 39,352 men from the Health Professionals Follow-Up Study (HPFS) [28], there was a nonstatistically significant inverse association (HR: 0.55, 95\% CI: 0.26-1.17) between baseline diabetes and subsequent self-reported AAA confirmed by medical record review. In 104,813 men and women from the Kaiser Multiphasic Health Checkup Cohort Study [29], history of diabetes was also nonsignificantly associated with a lower risk of AAA identified from hospitalization discharge diagnoses 
TABLE 2: Hazard ratio of clinically diagnosed AAA in association with baseline body mass index (BMI) overall and in subgroups.

\begin{tabular}{|c|c|c|c|c|c|}
\hline BMI categories & $N$ & Basic model $^{*}$ & $P$, interaction & Multivariable model $^{\dagger}$ & $P$, interaction \\
\hline \multicolumn{6}{|l|}{ All men } \\
\hline$<25 \mathrm{~kg} / \mathrm{m}^{2}$ & 174 & 1.00 (ref) & & 1.00 (ref) & \\
\hline $25-<30 \mathrm{~kg} / \mathrm{m}^{2}$ & 238 & $1.44(1.18-1.75)$ & & $1.30(1.06-1.59)$ & \\
\hline$\geq 30 \mathrm{~kg} / \mathrm{m}^{2}$ & 59 & $2.11(1.56-2.85)$ & & $1.69(1.24-2.30)$ & \\
\hline Age & & & 0.93 & & 0.89 \\
\hline \multicolumn{6}{|l|}{$<65$ years } \\
\hline$<25 \mathrm{~kg} / \mathrm{m}^{2}$ & 30 & 1.00 (ref) & & 1.00 (ref) & \\
\hline $25-<30 \mathrm{~kg} / \mathrm{m}^{2}$ & 49 & $1.35(0.86-2.13)$ & & $1.12(0.70-1.77)$ & \\
\hline$\geq 30 \mathrm{~kg} / \mathrm{m}^{2}$ & 18 & $2.16(1.20-3.88)$ & & $1.59(0.86-2.92)$ & \\
\hline \multicolumn{6}{|l|}{$\geq 65$ years } \\
\hline$<25 \mathrm{~kg} / \mathrm{m}^{2}$ & 144 & 1.00 (ref) & & 1.00 (ref) & \\
\hline $25-<30 \mathrm{~kg} / \mathrm{m}^{2}$ & 189 & $1.42(1.14-1.76)$ & & $1.31(1.05-1.63)$ & \\
\hline$\geq 30 \mathrm{~kg} / \mathrm{m}^{2}$ & 41 & $1.95(1.37-2.78)$ & & $1.62(1.13-2.33)$ & \\
\hline Smoking status & & & 0.70 & & 0.68 \\
\hline \multicolumn{6}{|l|}{ Never } \\
\hline$<25 \mathrm{~kg} / \mathrm{m}^{2}$ & 51 & 1.00 (ref) & & 1.00 (ref) & \\
\hline $25-<30 \mathrm{~kg} / \mathrm{m}^{2}$ & 59 & $1.33(0.91-1.95)$ & & $1.30(0.89-1.91)$ & \\
\hline$\geq 30 \mathrm{~kg} / \mathrm{m}^{2}$ & 10 & $1.53(0.77-3.05)$ & & $1.44(0.71-2.90)$ & \\
\hline \multicolumn{6}{|l|}{ Ever } \\
\hline$<25 \mathrm{~kg} / \mathrm{m}^{2}$ & 123 & 1.00 (ref) & & 1.00 (ref) & \\
\hline $25-<30 \mathrm{~kg} / \mathrm{m}^{2}$ & 178 & $1.35(1.07-1.70)$ & & $1.25(0.99-1.58)$ & \\
\hline$\geq 30 \mathrm{~kg} / \mathrm{m}^{2}$ & 49 & $1.94(1.39-2.72)$ & & $1.64(1.16-2.32)$ & \\
\hline Alcohol use & & & 0.40 & & 0.38 \\
\hline \multicolumn{6}{|l|}{ Less than daily } \\
\hline$<25 \mathrm{~kg} / \mathrm{m}^{2}$ & 85 & 1.00 (ref) & & 1.00 (ref) & \\
\hline $25-<30 \mathrm{~kg} / \mathrm{m}^{2}$ & 140 & $1.62(1.24-2.13)$ & & $1.49(1.13-1.96)$ & \\
\hline$\geq 30 \mathrm{~kg} / \mathrm{m}^{2}$ & 37 & $2.28(1.54-3.38)$ & & $1.84(1.23-2.76)$ & \\
\hline \multicolumn{6}{|l|}{ More than daily } \\
\hline$<25 \mathrm{~kg} / \mathrm{m}^{2}$ & 85 & 1.00 (ref) & & 1.00 (ref) & \\
\hline $25-<30 \mathrm{~kg} / \mathrm{m}^{2}$ & 95 & $1.30(0.97-1.75)$ & & $1.13(0.84-1.53)$ & \\
\hline$\geq 30 \mathrm{~kg} / \mathrm{m}^{2}$ & 22 & $2.17(1.35-3.50)$ & & $1.72(1.06-2.80)$ & \\
\hline Vigorous exercise & & & 0.63 & & 0.51 \\
\hline \multicolumn{6}{|c|}{ Less than once per week } \\
\hline$<25 \mathrm{~kg} / \mathrm{m}^{2}$ & 72 & $1.00(\mathrm{ref})$ & & 1.00 (ref) & \\
\hline $25-<30 \mathrm{~kg} / \mathrm{m}^{2}$ & 109 & $1.33(0.99-1.80)$ & & $1.27(0.93-1.72)$ & \\
\hline$\geq 30 \mathrm{~kg} / \mathrm{m}^{2}$ & 37 & $2.10(1.40-3.15)$ & & $1.87(1.23-2.84)$ & \\
\hline \multicolumn{6}{|c|}{ More than once per week } \\
\hline$<25 \mathrm{~kg} / \mathrm{m}^{2}$ & 101 & $1.00(\mathrm{ref})$ & & 1.00 (ref) & \\
\hline $25-<30 \mathrm{~kg} / \mathrm{m}^{2}$ & 128 & $1.48(1.14-1.92)$ & & $1.32(1.01-1.72)$ & \\
\hline$\geq 30 \mathrm{~kg} / \mathrm{m}^{2}$ & 21 & $1.79(1.11-2.87)$ & & $1.38(0.85-2.24)$ & \\
\hline Cardiovascular disease & & & 0.71 & & 0.68 \\
\hline \multicolumn{6}{|l|}{ No } \\
\hline$<25 \mathrm{~kg} / \mathrm{m}^{2}$ & 131 & $1.0(\mathrm{ref})$ & & 1.0 (ref) & \\
\hline $25-<30 \mathrm{~kg} / \mathrm{m}^{2}$ & 186 & $1.49(1.19-1.87)$ & & $1.35(1.08-1.70)$ & \\
\hline$\geq 30 \mathrm{~kg} / \mathrm{m}^{2}$ & 45 & $2.14(1.52-3.02)$ & & $1.72(1.21-2.45)$ & \\
\hline \multicolumn{6}{|l|}{ Yes } \\
\hline$<25 \mathrm{~kg} / \mathrm{m}^{2}$ & 43 & 1.0 (ref) & & 1.0 (ref) & \\
\hline $25-<30 \mathrm{~kg} / \mathrm{m}^{2}$ & 52 & $1.17(0.78-1.76)$ & & $1.11(0.73-1.68)$ & \\
\hline
\end{tabular}


TABLE 2: Continued.

\begin{tabular}{|c|c|c|c|c|c|}
\hline BMI categories & $N$ & Basic model $^{*}$ & $P$, interaction & Multivariable model $^{\dagger}$ & $P$, interaction \\
\hline$\geq 30 \mathrm{~kg} / \mathrm{m}^{2}$ & 14 & $1.68(0.90-3.14)$ & & $1.52(0.80-2.87)$ & \\
\hline Hypertension & & & 0.21 & & 0.25 \\
\hline \multicolumn{6}{|l|}{ No } \\
\hline$<25 \mathrm{~kg} / \mathrm{m}^{2}$ & 73 & 1.0 (ref) & & 1.0 (ref) & \\
\hline $25-<30 \mathrm{~kg} / \mathrm{m}^{2}$ & 79 & $1.37(0.99-1.88)$ & & $1.27(0.92-1.76)$ & \\
\hline$\geq 30 \mathrm{~kg} / \mathrm{m}^{2}$ & 21 & $2.82(1.72-4.62)$ & & $2.42(1.46-3.99)$ & \\
\hline \multicolumn{6}{|l|}{ Yes } \\
\hline$<25 \mathrm{~kg} / \mathrm{m}^{2}$ & 101 & 1.0 (ref) & & 1.0 (ref) & \\
\hline $25-<30 \mathrm{~kg} / \mathrm{m}^{2}$ & 158 & $1.34(1.04-1.73)$ & & $1.28(0.99-1.65)$ & \\
\hline$\geq 30 \mathrm{~kg} / \mathrm{m}^{2}$ & 38 & $1.53(1.04-2.25)$ & & $1.39(0.94-2.06)$ & \\
\hline Hypercholesterolemia & & & 0.33 & & 0.21 \\
\hline \multicolumn{6}{|l|}{ No } \\
\hline$<25 \mathrm{~kg} / \mathrm{m}^{2}$ & 81 & 1.0 (ref) & & 1.0 (ref) & \\
\hline $25-<30 \mathrm{~kg} / \mathrm{m}^{2}$ & 118 & $1.62(1.22-2.15)$ & & $1.50(1.12-2.00)$ & \\
\hline$\geq 30 \mathrm{~kg} / \mathrm{m}^{2}$ & 24 & $1.99(1.26-3.16)$ & & $1.59(0.99-2.55)$ & \\
\hline \multicolumn{6}{|l|}{ Yes } \\
\hline$<25 \mathrm{~kg} / \mathrm{m}^{2}$ & 91 & 1.0 (ref) & & 1.0 (ref) & \\
\hline $25-<30 \mathrm{~kg} / \mathrm{m}^{2}$ & 117 & $1.25(0.95-1.64)$ & & $1.12(0.85-1.49)$ & \\
\hline$\geq 30 \mathrm{~kg} / \mathrm{m}^{2}$ & 34 & $2.13(1.42-3.18)$ & & $1.75(1.16-2.66)$ & \\
\hline \multicolumn{6}{|l|}{ Diabetes } \\
\hline No & & & 0.27 & & 0.30 \\
\hline$<25 \mathrm{~kg} / \mathrm{m}^{2}$ & 161 & $1.0(\mathrm{ref})$ & & $1.0(\mathrm{ref})$ & \\
\hline $25-<30 \mathrm{~kg} / \mathrm{m}^{2}$ & 216 & $1.45(1.18-1.78)$ & & $1.32(1.07-1.63)$ & \\
\hline$\geq 30 \mathrm{~kg} / \mathrm{m}^{2}$ & 54 & $2.31(1.69-3.16)$ & & $1.84(1.34-2.53)$ & \\
\hline \multicolumn{6}{|l|}{ Yes } \\
\hline$<25 \mathrm{~kg} / \mathrm{m}^{2}$ & 13 & 1.0 (ref) & & 1.0 (ref) & \\
\hline $25-<30 \mathrm{~kg} / \mathrm{m}^{2}$ & 22 & $1.21(0.60-2.42)$ & & $1.00(0.49-2.03)$ & \\
\hline$\geq 30 \mathrm{~kg} / \mathrm{m}^{2}$ & 5 & $0.91(0.31-2.69)$ & & $0.69(0.23-2.07)$ & \\
\hline
\end{tabular}

${ }^{*}$ Model adjusted for age, race, randomized treatment assignment (aspirin, $\beta$-carotene, vitamin $\mathrm{E}$, vitamin $\mathrm{C}$, multivitamin).

${ }^{\dagger}$ Model additionally adjusted for smoking status (never, past, current), alcohol use (none, monthly, weekly, daily), vigorous exercise (<1 time/week, 1-2 times/week, 3-4 times/week, 5-7 times/week), history of hypertension, hypercholesterolemia, cardiovascular disease, and diabetes (each yes, no), unless in the specific subgroup.

and/or repair procedures (HR: 0.62, 95\% CI: 0.36-1.05). Furthermore, in a study using Taiwanese insurance data, the incidence rate of thoracic and abdominal aortic aneurysm was significantly lower (HR: $0.64,95 \%$ CI: $0.56-0.74$ ) in 160,391 patients with diabetes compared with 646,710 subjects without diabetes [30]. Other studies [31-35], including the Tromso study that screened all participants by ultrasonography at baseline and 7-year follow-up to assess AAA [34], found no association of impaired glucose tolerance or blood glucose level with incident AAA morbidity or mortality, before or after adjustment for other risk factors. Finally, a meta-analysis that combined data from 6 prospective studies published between 1993 and 2013 found a significant lower incidence of AAA in diabetic versus nondiabetic individuals (odds ratio: 0.54, 95\% CI: 0.31-0.91; $P=0.03$ ) [36].

In the present study, we found a significant inverse association of diabetes history with AAA diagnosed after
$>2$ years of follow-up. Laboratory studies have provided biological plausibility that diabetes may reduce the risk of AAA during prolonged period of time. The hyperglycemiainduced advanced glycation leads to cross-linking of elastin and collagen in the extracellular matrix within abdominal aorta wall [37]. This alteration inhibits secretion of metalloproteinases and prevents excessive proteolysis, a key process in formation and progression of AAA [17]. Hyperglycemia also modulates expression of thrombosis and fibrinolysis factors [38], which may reduce clot degradation and renewal of intraluminal thrombus in AAA and thus improve aneurysmal wall stability and slow the rate of expansion [39, 40]. Exposure to glycated and cross-linked collagen lattices also limits chronic inflammation to the intima and protect the media from matrix degradation [41]. Alternatively, lifestyle changes after diabetes diagnosis, such as smoking cessation, weight control and exercise, and medication treatment for 
TABLE 3: Hazard ratio of clinically diagnosed AAA in association with baseline history of diabetes overall and in subgroups.

\begin{tabular}{|c|c|c|c|c|c|}
\hline Diabetes (yes versus no) & $N$ & Basic model $^{*}$ & $P$, interaction & Multivariable model $^{\dagger}$ & $P$, interaction \\
\hline All men & 471 & $1.08(0.78-1.50)$ & & $0.79(0.57-1.11)$ & \\
\hline Age & & & 0.59 & & 0.41 \\
\hline$<65$ years & 97 & $0.75(0.27-2.05)$ & & $0.45(0.16-1.26)$ & \\
\hline$\geq 65$ years & 374 & $1.10(0.78-1.56)$ & & $0.86(0.61-1.22)$ & \\
\hline Smoking status & & & 0.59 & & 0.51 \\
\hline Never & 120 & $0.82(0.38-1.77)$ & & $0.65(0.30-1.42)$ & \\
\hline Ever & 350 & $1.08(0.75-1.55)$ & & $0.84(0.58-1.21)$ & \\
\hline Alcohol use & & & 0.73 & & 0.74 \\
\hline Less than daily & 262 & $1.17(0.78-1.75)$ & & $0.86(0.57-1.30)$ & \\
\hline More than daily & 202 & $0.98(0.55-1.76)$ & & $0.72(0.40-1.30)$ & \\
\hline Vigorous exercise & & & 0.36 & & 0.33 \\
\hline Less than once per week & 218 & $1.19(0.78-1.81)$ & & $0.91(0.60-1.40)$ & \\
\hline More than once per week & 250 & $0.85(0.49-1.46)$ & & $0.62(0.36-1.08)$ & \\
\hline Hypertension & & & 0.77 & & 0.90 \\
\hline No & 173 & $1.22(0.64-2.32)$ & & $0.80(0.42-1.54)$ & \\
\hline Yes & 297 & $0.94(0.64-1.37)$ & & $0.81(0.55-1.18)$ & \\
\hline Hypercholesterolemia & & & 0.99 & & 0.98 \\
\hline No & 223 & $1.05(0.63-1.76)$ & & $0.81(0.48-1.36)$ & \\
\hline Yes & 242 & $1.06(0.70-1.62)$ & & $0.80(0.52-1.24)$ & \\
\hline Cardiovascular disease & & & 0.41 & & 0.58 \\
\hline No & 362 & $1.09(0.73-1.62)$ & & $0.83(0.55-1.25)$ & \\
\hline Yes & 109 & $0.80(0.46-1.41)$ & & $0.74(0.42-1.32)$ & \\
\hline
\end{tabular}

diabetes including metformin [42] and rosiglitazone [43], may also have favorable effects against AAA development and explain the lower risk during longer-term follow-up.

Our study also found an association between greater BMI and an increased risk of AAA, consistent across varying cardiovascular risk factor profiles. Though multiple lifestyle factors correlated with obesity may explain this association, there is evidence that pathogenic processes related to obesity, such as the release of adipokines and obesity-induced aortic inflammation, may lead to vessel weakening and subsequent aneurysmal formation [44]. Previous prospective studies of obesity and AAA have obtained contradictory results. The HPFS [28] and Whitehall study [35] each reported a positive association of baseline BMI with subsequent AAA determined by review of medical records or death certificates, a finding consistent with ours. The Kaiser study [29] and two population-based Swedish cohort studies [45] found a borderline significant positive association of abdominal obesity, defined by waist circumference or Sagittal abdominal diameter, with AAA identified from hospitalization discharge diagnoses and/or death registries. However, in four other studies $[27,33,34,46]$, including two studies that performed standardized ultrasound scans to assess AAA based on aortic diameter $[34,46]$, measures of obesity at baseline were not associated with incident AAA during follow-up.
Strengths of our study include the prospective analysis, a large number of diagnosed AAA cases, and comprehensive information on covariates. However, an important methodologic consideration of our study is the ascertainment of AAA by self-reported clinical diagnosis on questionnaires. Since participants were not screened, majority of cases identified in our study are likely symptomatic AAA. Missing of asymptomatic and undiagnosed cases may lead to underestimation of the disease rate in our study. On the other hand, since the PHS participants are US male physicians, the self-reported disease outcomes have been fairly well validated by medical record review, with confirmation rates among records reviewed ranging from $60 \%$ to $80 \%$ for major CVD and cancers. Despite the limitation in outcome ascertainment, our study provides relevant data on risk factors for clinically manifest AAA. Our finding of an association between BMI and AAA suggests that obesity could potentially be an independent risk factor. Nevertheless, more studies are needed in women and diverse populations to confirm this finding and determine appropriate AAA screening recommendations based on obesity status. In contrast, the unclear and inconclusive relation between diabetes history and subsequent AAA argues against change in current guidelines for AAA screening and management with regard to diabetes status. 
Other limitations of this study are also noted. First, although the validity of self-reported disease outcomes [47] and anthropometries [48] in health professionals is high, we cannot rule out random error in these measurements. In addition, our analyses were confined to baseline BMI and history of diabetes, with no data on the duration of exposures or changes over time. These random misclassifications would tend to bias the estimate of associations toward the null. Second, although the male physicians in PHS were less likely to overreport a diagnosis of AAA, elderly men with diabetes or obesity are subject to more intense medical care and closer surveillance, and thereafter the likelihood of finding vascular complications including AAA might be higher. Third, limited by the existing data, we cannot further examine the association with history of diabetes according to diagnosis criteria, type and duration of treatment, and presence of complications. Finally, the PHS cohort consists of predominantly white, elderly US men. Findings from this study may not be generalizable to women and other populations.

\section{Conclusion}

In this large, prospective cohort of US male physicians, we found that obesity was positively associated with risk of clinically diagnosed AAA. There is suggestive evidence that history of diabetes may be associated with a lower risk of AAA over long-term follow-up. Additional studies are warranted to confirm or refute these associations.

\section{Disclosure}

These funding sources have no role in design and conduct of the study; collection, management, analysis, and interpretation of the data; and preparation, review, or approval of the manuscript. Dr. Lu Wang has full access to all of the data in the study and takes responsibility for the integrity of the data and the accuracy of the data analysis.

\section{Competing Interests}

Dr. Lu Wang was supported by a K99/R00 grant HL095649 from the National Heart, Lung, and Blood Institutes (NHLBI), the National Institutes of Health (NIH). Dr. Howard D. Sesso has received investigator-initiated research funding from the NIH, Pfizer Inc., Mars Symbioscience, and the Council for Responsible Nutrition Foundation. Dr. JoAnn E. Manson has received investigator-initiated research funding from the NIH and Mars Symbioscience and assistance with study pills and packaging from Pronova BioPharma/BASF and Pharmavite for the VITamin D and OmegA-3 TriaL. Dr. J. Michael Gaziano has received investigator-initiated research funding from the NIH, the Veterans Administration, and BASF Corporation to assist in the establishment of this trial cohort; assistance with study agents and packaging from BASF Corporation and Pfizer (formerly Wyeth, American Home Products, and Lederle); and assistance with study packaging provided by
DSM Nutritional Products Inc. (formerly Roche Vitamins). No other authors reported any competing interests.

\section{Acknowledgments}

The authors are deeply indebted to the 22,071 participants of PHS I and 14,641 participants of PHS II for their longstanding dedication and conscientious collaboration. They also acknowledge the contributions of Gregory Kotler and Natalya Gomelskaya to the statistical analysis of this study. This work was supported by grants (CA 97193, CA 34944, CA 40360, HL 26490, and HL 34595) from the National Institutes of Health (Bethesda, MD) and an investigator-initiated grant from BASF Corporation (Florham Park, NJ). Study agents and packaging in the PHS were provided by BASF Corporation, Pfizer (formerly Wyeth, American Home Products, and Lederle) (New York, NY), and DSM Nutritional Products, Inc. (formerly Roche Vitamins) (Parsippany, NJ).

\section{References}

[1] P. Sandiford, D. Mosquera, and D. Bramley, "Trends in incidence and mortality from abdominal aortic aneurysm in New Zealand," British Journal of Surgery, vol. 98, no. 5, pp. 645-651, 2011.

[2] R. Darwood, J. J. Earnshaw, G. Turton et al., "Twenty-year review of abdominal aortic aneurysm screening in men in the county of Gloucestershire, United Kingdom," Journal of Vascular Surgery, vol. 56, no. 1, pp. 8-13, 2012.

[3] D. P. J. Howard, A. Banerjee, J. F. Fairhead, A. Handa, L. E. Silver, and P. M. Rothwell, "Age-specific incidence, risk factors and outcome of acute abdominal aortic aneurysms in a defined population," British Journal of Surgery, vol. 102, no. 8, pp. 907915, 2015.

[4] A. Reite, K. Soreide, C. L. Ellingsen, J. T. Kvaløy, and M. Vetrhus, "Epidemiology of ruptured abdominal aortic aneurysms in a well-defined Norwegian population with trends in incidence, intervention rate, and mortality," Journal of Vascular Surgery, vol. 61, no. 5, pp. 1168-1174, 2015.

[5] J. J. Reimerink, M. J. Van Der Laan, M. J. Koelemay, R. Balm, and D. A. Legemate, "Systematic review and meta-analysis of population-based mortality from ruptured abdominal aortic aneurysm," British Journal of Surgery, vol. 100, no. 11, pp. 14051413, 2013.

[6] J. S. Lindholt, R. Søgaard, and J. Laustsen, "Prognosis of ruptured abdominal aortic aneurysms in Denmark from 19942008," Clinical Epidemiology, vol. 4, no. 1, pp. 111-113, 2012.

[7] I. M. Nordon, R. J. Hinchliffe, P. J. Holt, I. M. Loftus, and M. W. Thompson, "Review of current theories for abdominal aortic aneurysm pathogenesis," Vascular, vol. 17, no. 5, pp. 253-263, 2009.

[8] J. Golledge and P. E. Norman, "Atherosclerosis and abdominal aortic aneurysm: cause, response, or common risk factors?" Arteriosclerosis, Thrombosis, and Vascular Biology, vol. 30, no. 6, pp. 1075-1077, 2010.

[9] F. A. Lederle, G. R. Johnson, S. E. Wilson et al., "Prevalence and associations of abdominal aortic aneurysm detected through screening," Annals of Internal Medicine, vol. 126, no. 6, pp. 441449, 1997. 
[10] F. A. Lederle, G. R. Johnson, S. E. Wilson et al., "The aneurysm detection and management study screening program: validation cohort and final results," Archives of Internal Medicine, vol. 160, no. 10, pp. 1425-1430, 2000.

[11] M. T. Q. Le, K. Jamrozik, T. M. E. Davis, and P. E. Norman, "Negative association between infra-renal aortic diameter and glycaemia: the Health in Men Study," European Journal of Vascular and Endovascular Surgery, vol. 33, no. 5, pp. 599-604, 2007.

[12] K. C. Kent, R. M. Zwolak, N. N. Egorova et al., "Analysis of risk factors for abdominal aortic aneurysm in a cohort of more than 3 million individuals," Journal of Vascular Surgery, vol. 52, no. 3 , pp. 539-548, 2010.

[13] S. Svensjö, M. Björck, M. Gürtelschmid, K. Djavani Gidlund, A. Hellberg, and A. Wanhainen, "Low prevalence of abdominal aortic aneurysm among 65-year-old swedish men indicates a change in the epidemiology of the disease," Circulation, vol. 124, no. 10, pp. 1118-1123, 2011.

[14] I. Baumgartner, A. T. Hirsch, M. T. B. Abola et al., "Cardiovascular risk profile and outcome of patients with abdominal aortic aneurysm in out-patients with atherothrombosis: data from the reduction of atherothrombosis for continued Health (REACH) registry," Journal of Vascular Surgery, vol. 48, no. 4, pp. 808814.el, 2008.

[15] A. R. Brady, S. G. Thompson, F. G. R. Fowkes, R. M. Greenhalgh, and J. T. Powell, "Abdominal aortic aneurysm expansion: risk factors and time intervals for surveillance," Circulation, vol. 110, no. 1, pp. 16-21, 2004.

[16] M. Vega de Céniga, R. Gómez, L. Estallo, L. Rodríguez, M. Baquer, and A. Barba, "Growth rate and associated factors in small abdominal aortic aneurysms," European Journal of Vascular and Endovascular Surgery, vol. 31, no. 3, pp. 231-236, 2006.

[17] J. Golledge, M. Karan, C. S. Moran et al., "Reduced expansion rate of abdominal aortic aneurysms in patients with diabetes may be related to aberrant monocyte-matrix interactions," European Heart Journal, vol. 29, no. 5, pp. 665-672, 2008.

[18] A. Thompson, J. A. Cooper, M. Fabricius, S. E. Humphries, H. A. Ashton, and H. Hafez, "An analysis of drug modulation of abdominal aortic aneurysm growth through 25 years of surveillance," Journal of Vascular Surgery, vol. 52, no. 1, pp. 5561.e2, 2010.

[19] J. K. Giacovelli, N. Egorova, R. Nowygrod, A. Gelijns, K. C. Kent, and N. J. Morrissey, "Insurance status predicts access to care and outcomes of vascular disease," Journal of Vascular Surgery, vol. 48, no. 4, pp. 905-911.el, 2008.

[20] O. Cronin, P. J. Walker, and J. Golledge, "The association of obesity with abdominal aortic aneurysm presence and growth," Atherosclerosis, vol. 226, no. 2, pp. 321-327, 2013.

[21] M. J. Sweeting, S. G. Thompson, L. C. Brown, and J. T. Powell, "Meta-analysis of individual patient data to examine factors affecting growth and rupture of small abdominal aortic aneurysms," British Journal of Surgery, vol. 99, no. 5, pp. 655$665,2012$.

[22] O. Stackelberg, M. Björck, O. Sadr-Azodi, S. C. Larsson, N. Orsini, and A. Wolk, "Obesity and abdominal aortic aneurysm," The British Journal of Surgery, vol. 100, no. 3, pp. 360-366, 2013.

[23] Steering Committee of the Physicians' Health Study Research Group, "Final report on the aspirin component of the ongoing Physicians' Health Study," The New England Journal of Medicine, vol. 321, pp. 129-135, 1989.
[24] W. G. Christen, J. M. Gaziano, and C. H. Hennekens, "Design of Physicians' Health Study II-a randomized trial of betacarotene, vitamins $\mathrm{E}$ and $\mathrm{C}$, and multivitamins, in prevention of cancer, cardiovascular disease, and eye disease, and review of results of completed trials," Annals of Epidemiology, vol. 10, no. 2, pp. 125-134, 2000.

[25] M. S. Freiberg, A. M. Arnold, A. B. Newman, M. S. Edwards, K. L. Kraemer, and L. H. Kuller, "Abdominal aortic aneurysms, increasing infrarenal aortic diameter, and risk of total mortality and incident cardiovascular disease events: 10-year follow-up data from the cardiovascular health study," Circulation, vol. 117, no. 8, pp. 1010-1017, 2008.

[26] L. Djoussé, J. A. Driver, J. M. Gaziano, J. E. Buring, and I. M. Lee, "Association between modifiable lifestyle factors and residual lifetime risk of diabetes," Nutrition, Metabolism and Cardiovascular Diseases, vol. 23, no. 1, pp. 17-22, 2013.

[27] F. A. Lederle, J. C. Larson, K. L. Margolis et al., "Abdominal aortic aneurysm events in the women's health initiative: cohort study," BMJ, vol. 337, Article ID al724, 2008.

[28] D. R. Wong, W. C. Willett, and E. B. Rimm, "Smoking, hypertension, alcohol consumption, and risk of abdominal aortic aneurysm in men," American Journal of Epidemiology, vol. 165, no. 7, pp. 838-845, 2007.

[29] C. Iribarren, J. A. Darbinian, A. S. Go, B. H. Fireman, C. D. Lee, and D. P. Grey, "Traditional and novel risk factors for clinically diagnosed abdominal aortic aneurysm: the Kaiser multiphasic health checkup cohort study," Annals of Epidemiology, vol. 17, no. 9, pp. 669-678, 2007.

[30] C.-L. Tsai, C.-L. Lin, Y.-Y. Wu, D.-C. Shieh, F.-C. Sung, and C.H. Kao, "Advanced complicated diabetes mellitus is associated with a reduced risk of thoracic and abdominal aortic aneurysm rupture: a population-based cohort study," Diabetes/Metabolism Research and Reviews, vol. 31, no. 2, pp. 190-197, 2015.

[31] M. B. Rodin, M. L. Daviglus, G. C. Wong et al., "Middle age cardiovascular risk factors and abdominal aortic aneurysm in older age," Hypertension, vol. 42, no. 1, pp. 61-68, 2003.

[32] M. E. Törnwall, J. Virtamo, J. K. Haukka, D. Albanes, and J. K. Huttunen, "Life-style factors and risk for abdominal aortic aneurysm in a cohort of Finnish male smokers," Epidemiology, vol. 12, no. 1, pp. 94-100, 2001.

[33] D. Reed, C. Reed, G. Stemmermann, and T. Hayashi, "Are aortic aneurysms caused by atherosclerosis?" Circulation, vol. 85, no. 1, pp. 205-211, 1992.

[34] S. H. Forsdahl, K. Singh, S. Solberg, and B. K. Jacobsen, "Risk factors for abdominal aortic aneurysms: a 7-year prospective study: the tromsø study, 1994-2001," Circulation, vol. 119, no. 16, pp. 2202-2208, 2009.

[35] D. P. Strachan, "Predictors of death from aortic aneurysm among middle-aged men: the Whitehall study," British Journal of Surgery, vol. 78, no. 4, pp. 401-404, 1991.

[36] P. De Rango, L. Farchioni, B. Fiorucci, and M. Lenti, "Diabetes and abdominal aortic aneurysms," European Journal of Vascular and Endovascular Surgery, vol. 47, no. 3, pp. 243-261, 2014.

[37] K. L. Rensing and T. B. Twickler, "Abdominal aorta aneurysm: an exceptional expression of atherosclerotic disease in type II diabetes," European Heart Journal, vol. 29, no. 5, pp. 581-582, 2008.

[38] M. M. Dua, N. Miyama, J. Azuma et al., "Hyperglycemia modulates plasminogen activator inhibitor-1 expression and aortic diameter in experimental aortic aneurysm disease," Surgery, vol. 148, no. 2, pp. 429-435, 2010. 
[39] E. J. Dunn, R. A. S. Ariëns, and P. J. Grant, "The influence of type 2 diabetes on fibrin structure and function," Diabetologia, vol. 48, no. 6, pp. 1198-1206, 2005.

[40] X. Houard, F. Rouzet, Z. Touat et al., “Topology of the fibrinolytic system within the mural thrombus of human abdominal aortic aneurysms," Journal of Pathology, vol. 212, no. 1, pp. 2028, 2007.

[41] K. Shimizu, R. N. Mitchell, and P. Libby, "Inflammation and cellular immune responses in abdominal aortic aneurysms," Arteriosclerosis, Thrombosis, and Vascular Biology, vol. 26, no. 5, pp. 987-994, 2006.

[42] L. Li, J.-C. Mamputu, N. Wiernsperger, and G. Renier, "Signaling pathways involved in human vascular smooth muscle cell proliferation and matrix metalloproteinase- 2 expression induced by leptin: inhibitory effect of metformin," Diabetes, vol. 54, no. 7, pp. 2227-2234, 2005.

[43] S. M. Haffner, A. S. Greenberg, W. M. Weston, H. Chen, K. Williams, and M. I. Freed, "Effect of rosiglitazone treatment on nontraditional markers of cardiovascular disease in patients with type 2 diabetes mellitus," Circulation, vol. 106, no. 6, pp. 679-684, 2002.

[44] T. K. Chatterjee, L. L. Stoll, G. M. Denning et al., "Proinflammatory phenotype of perivascular adipocytes: influence of high-fat feeding," Circulation Research, vol. 104, no. 4, pp. 541-549, 2009.

[45] O. Stackelberg, M. Björck, O. Sadr-Azodi, S. C. Larsson, N. Orsini, and A. Wolk, "Obesity and abdominal aortic aneurysm," British Journal of Surgery, vol. 100, no. 3, pp. 360-366, 2013.

[46] A. J. Lee, F. G. R. Fowkes, M. N. Carson, G. C. Leng, and P. L. Allan, "Smoking, atherosclerosis and risk of abdominal aortic aneurysm," European Heart Journal, vol. 18, no. 4, pp. 671-676, 1997.

[47] G. A. Colditz, P. Martin, M. J. Stampfer et al., "Validation of questionnaire information on risk factors and disease outcomes in a prospective cohort study of women," American Journal of Epidemiology, vol. 123, no. 5, pp. 894-900, 1986.

[48] E. B. Rimm, M. J. Stampfer, G. A. Colditz, C. G. Chute, L. B. Litin, and W. C. Willett, "Validity of self-reported waist and hip circumferences in men and women," Epidemiology, vol. 1, no. 6, pp. 466-473, 1990. 


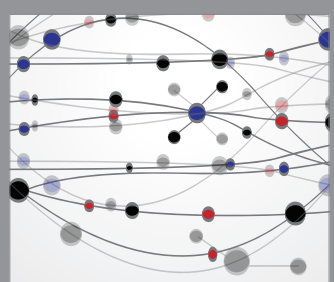

The Scientific World Journal
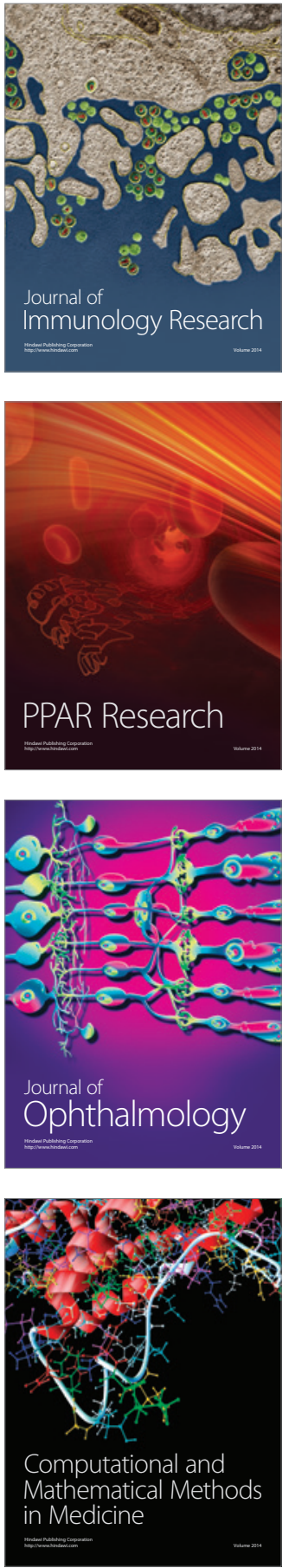

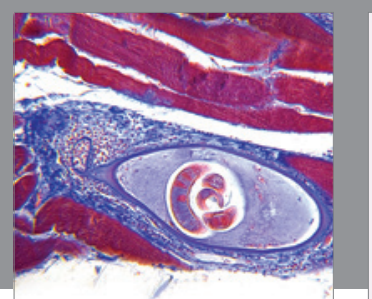

Gastroenterology Research and Practice
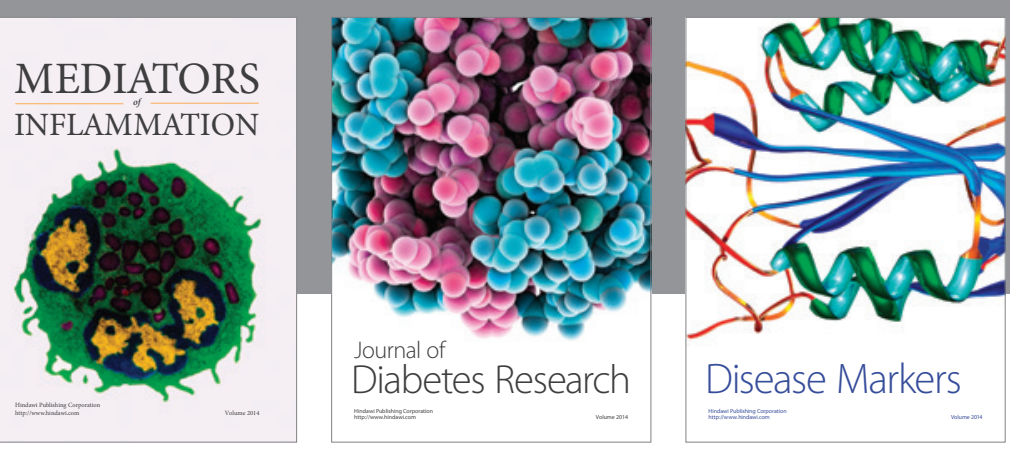

Disease Markers

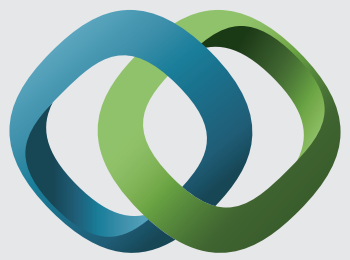

\section{Hindawi}

Submit your manuscripts at

https://www.hindawi.com
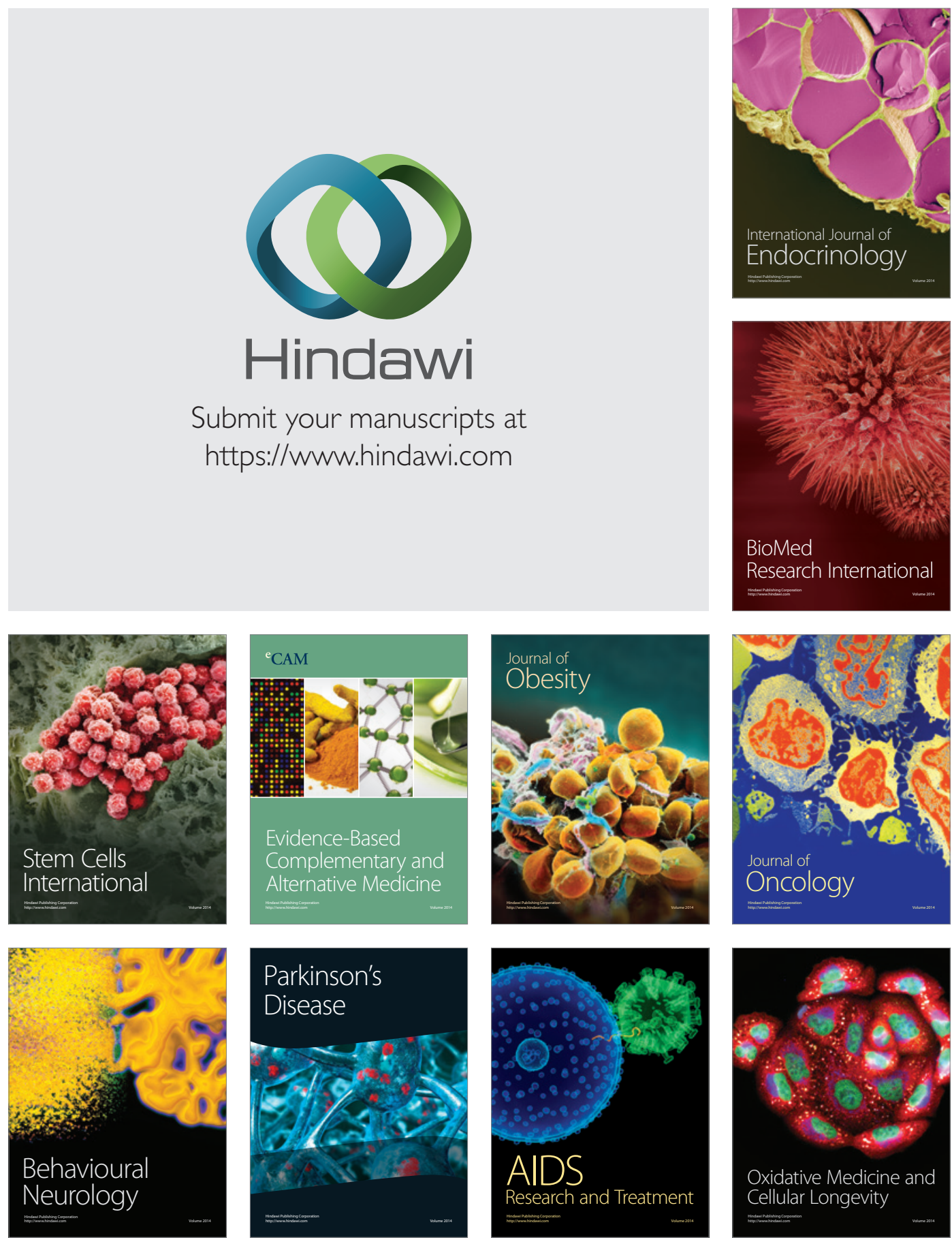